\title{
Voronoi Analysis of the Structure of Ni-Zr-Al Ternary Metallic Glass
}

\author{
T. Fukunaga ${ }^{1, *}$, K. Itoh ${ }^{1}$, T. Otomo ${ }^{2}$, K. Mori ${ }^{1}$, M. Sugiyama ${ }^{1}$, H. Kato ${ }^{3}$, \\ M. Hasegawa ${ }^{3}$, A. Hirata ${ }^{4}$, Y. Hirotsu ${ }^{4}$ and A. C. Hannon ${ }^{5}$ \\ ${ }^{1}$ Research Reactor Institute, Kyoto University, Sennan-gun, Osaka 590-0494, Japan \\ ${ }^{2}$ Institute of Material Structure Science, KEK, Tsukuba 305, Japan \\ ${ }^{3}$ Institute for Material Research, Tohoku University, Sendai 980-8577, Japan \\ ${ }^{4}$ The Institute of Scientific and Industrial Research, Osaka University, Ibaraki 567-0047, Japan \\ ${ }^{5}$ ISIS Facility, Rutherford Appleton Laboratory, Chilton, Didcot, Oxon OX11 OQX, UK
}

\begin{abstract}
$\mathrm{Ni}-\mathrm{Zr}$ metallic glasses have been recognized to be unstable in comparison with $\mathrm{Cu}-\mathrm{Zr}$ metallic glasses. An analysis of Voronoi polyhedra in the RMC simulations based on the diffraction data could characterize the atomic configurations around $\mathrm{Ni}$ and $\mathrm{Cu}$ atoms. The polyhedra around $\mathrm{Ni}$ atoms are dominated by trigonal prism-like, Archimedian antiprism-like, and similar polyhedra. In contrast, icosahedron-like polyhedra are preferred for $\mathrm{Cu}$. The Ni-Zr glasses have been reported to stabilize by adding Al. Therefore, in this work, the analysis of Voronoi polyhedra around $\mathrm{Ni}, \mathrm{Zr}$ and $\mathrm{Al}$ atoms for $\mathrm{Ni}_{25} \mathrm{Zr}_{60} \mathrm{Al}_{15}$ ternary metallic glass was carried out in order to clarify the difference between the atomic structures for the binary and ternary metallic glasses. Trigonal prism-like, Archimedian antiprism-like and similar polyhedra, which are dominated in the $\mathrm{Ni}-\mathrm{Zr}$ metallic glasses, decreased in number by adding $\mathrm{Al}$ to the $\mathrm{Ni}-\mathrm{Zr}$ system. On the contrary, the number of icosahedron-like polyhedra was found to increase. The results apparently indicate that the addition of $\mathrm{Al}$ into Ni-Zr binary system promote the formation of icosahedron-like polyhedra in the structure. Therefore, from these results, we can easily recognize that icosahedron-like polyhedra play an important role to stabilize the structure of metallic glasses. [doi:10.2320/matertrans.MJ200750]
\end{abstract}

(Received November 24, 2006; Accepted December 27, 2006; Published June 20, 2007)

Keywords: glasses, metallic, rapid solidification processing, simulations, Monte Carlo, diffraction

\section{Introduction}

Bulk metallic glasses have received much attention in order to have a large number of technical applications as high strength structural materials. It is well known that the metallic glasses become stable by addition of third, forth and fifth elements to the binary system. For example, it has been reported that the glass transition in the $\mathrm{Ni}-\mathrm{Zr}$ metallic glass is observed in a wide compositional range by addition of small amount of Al. ${ }^{1)}$ Structural investigation for Ni-Zr-Al metallic glasses has informed us of the change in the local structure by addition of $\mathrm{Al}^{2)}$ That is, the coordination number of 12.5 around $\mathrm{Zr}$ for $\mathrm{Zr}_{60} \mathrm{Ni}_{25} \mathrm{Al}_{15}$ metallic glass is much different from that of 10.7 for $\mathrm{Zr}_{70} \mathrm{Ni}_{30}$ metallic glass. However, the result only suggests the formation of icosahedral local configuration in $\mathrm{Zr}_{60} \mathrm{Ni}_{25} \mathrm{Al}_{15}$ metallic glass and no detailed topological information has reported.

In this work, we have investigated the topology of the atomic configurations in $\mathrm{Ni}_{33.3} \mathrm{Zr}_{66.7}$ binary and $\mathrm{Ni}_{25} \mathrm{Zr}_{60} \mathrm{Al}_{15}$ ternary metallic glasses by using a combination of neutron \& X-ray diffraction data and Reverse Monte Carlo (RMC) modeling. ${ }^{3)}$ Time-of-flight (T-O-F) neutron diffraction using neutrons of short-wavelength and X-ray diffraction with photon energy of $113.68 \mathrm{keV}$ were employed to make high real-space resolution measurements on the atomic configurations of $\mathrm{Ni}_{33.3} \mathrm{Zr}_{66.7}$ and $\mathrm{Ni}_{25} \mathrm{Zr}_{60} \mathrm{Al}_{15}$ metallic glasses. RMC modeling has been recognized to be an excellent method for visualizing the three-dimensional atomic arrangement of liquid and amorphous materials, based on the results of neutron \& X-ray diffraction experiments. Therefore, in this study RMC modeling based on the neutron \& X-ray diffraction data was carried out for constructing the atomic configurations of the $\mathrm{Ni}_{33.3} \mathrm{Zr}_{66.7}$ and $\mathrm{Ni}_{25} \mathrm{Zr}_{60} \mathrm{Al}_{15}$ metallic glasses and for investigating the topological characteristics.

*Fax: +81-724-51-2635, E-mail: tfuku@rri.kyoto-u.ac.jp

\section{Experimental}

$\mathrm{Ni}_{33.3} \mathrm{Zr}_{66.7}$ binary and $\mathrm{Ni}_{25} \mathrm{Zr}_{60} \mathrm{Al}_{15}$ ternary alloys were prepared by arc melting using $\mathrm{Ni}(99.9 \%), \mathrm{Zr}$ (>99.9\%) and Al (99.99\%). Metallic glass ribbons were synthesized by rapid quenching from the molten state using a single roller technique under Ar gas atmosphere. The density of the metallic glass was measured by gas pycnometer (Micrometritics, Accupyc 1330) with He gas (99.999\%) at room temperature.

The neutron diffraction experiment was carried out by using the High Intensity Total scattering spectrometer HIT-II at the High Energy Accelerator Research Organization (KEK), Tsukuba, Japan. The measurement of the structure factor, $S(Q)$, over a wide $Q$ range (from $Q=5 \mathrm{~nm}^{-1}$ up to $200 \mathrm{~nm}^{-1}$ in this case), leading to a high resolution in realspace, can be obtained by time-of-flight neutron diffraction using a spallation neutron source. The samples (about $2 \mathrm{~g}$ ) were put into the vanadium cells $(8 \mathrm{~mm}$ in inside diameter, $40 \mathrm{~mm}$ in height and $0.025 \mathrm{~mm}$ in wall thickness) for measuring the scattering intensity. The intensity was corrected for the cell, background, absorption and, multiple and incoherent scattering. The obtained coherent scattering intensity, $I(Q)$, was normalized with the scattering intensity from a vanadium rod as standard.

The X-ray diffraction measurement was carried out with photon energy of $113.68 \mathrm{keV}$ at the high-energy X-ray diffraction beam line BL04B2 in the SPring-8, Mikazukicho, Hyogo, Japan. The sample was put into a flat container of $2 \mathrm{~mm}$ thickness with Kapton windows. After corrections for polarization, absorption and Compton scattering, the $I(Q)$ was converted into $S(Q)$, over a wide $Q$ range (from $Q=5$ $\mathrm{nm}^{-1}$ up to $\left.200 \mathrm{~nm}^{-1}\right)$.

The $S(Q)$ of a multi-component system according to the Faber-Ziman definition ${ }^{4)}$ is derived as follows; 

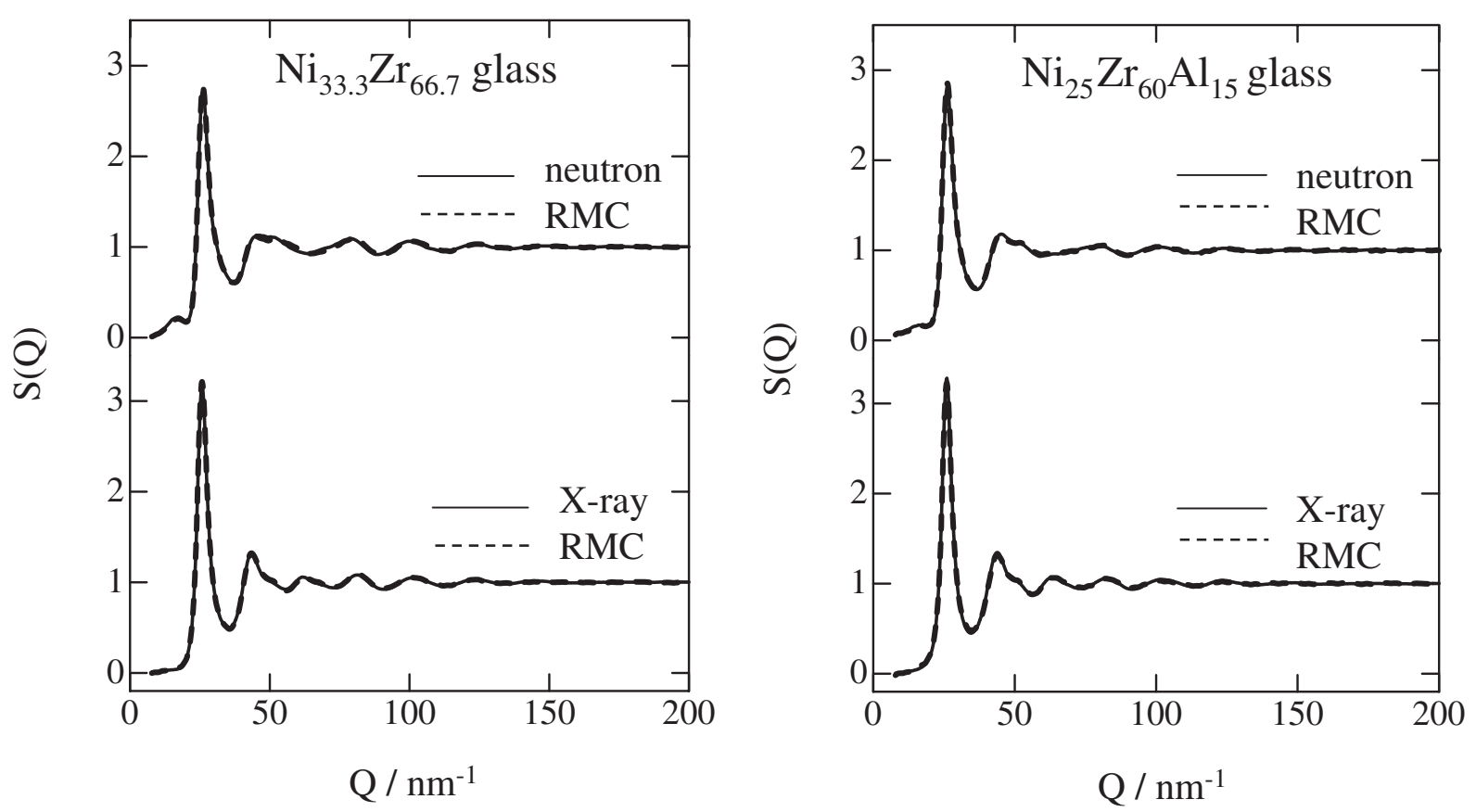

Fig. 1 Structure factors, $S(Q)$, observed by neutron diffraction (solid line) and Reverse Monte Carlo (RMC) fits (dashed line) for $\mathrm{Ni}_{33.3} \mathrm{Zr}_{66.7}$ (a) and $\mathrm{Ni}_{25} \mathrm{Zr}_{60} \mathrm{Al}_{15}$ (b) metallic glasses.

$$
I(Q)=N\langle b\rangle^{2} S(Q)+N\left(\left\langle b^{2}\right\rangle-\langle b\rangle^{2}\right),
$$

where $I(Q)$ is the coherent intensity, $Q$ is the magnitude of the scattering vector, $N$ is number of atoms and

$$
\left\langle b^{2}\right\rangle=\sum_{i} C_{i} b_{i}^{2}, \quad\langle b\rangle=\sum_{i} C_{i} b_{i},
$$

in which $C_{i}$ and $b_{i}$ are respectively the concentration and the coherent neutron scattering length (atomic scattering factor for X-ray) of element $i$. The structure factor,

$$
S(Q)=\frac{1}{\langle b\rangle^{2}} \sum_{i, j=1}^{n} C_{i} C_{j} b_{i} b_{j} S_{i j}(Q),
$$

where $S_{i j}(Q)$ is the partial structure factor $(i$ and $j$ each refer to either of the elements in the sample). $S_{i j}(Q)$ is related to the partial pair correlation function, $g_{i j}(r)$, for correlations between atoms of element $i$ and of element $j$, by Fourier transformation,

$$
Q\left(S_{i j}(Q)-1\right)=4 \pi \rho_{o} \int_{0}^{Q_{\max }} r\left(g_{i j}(r)-1\right) \sin (Q r) d r,
$$

where $\rho_{o}$ is the atomic number density of the sample.

Reverse Monte Carlo (RMC) modeling ${ }^{3)}$ based on the diffraction data is a simple variant of the standard Monte Carlo procedure, but a powerful method for deriving threedimensional atomic arrangements of disordered materials. The atoms in a periodic model are moved at random and the moves are accepted or rejected in such a way as to minimize the difference between experiment and simulation, expressed as

$$
\chi^{2}=\sum_{i=1}^{m}\left[S_{r m c}\left(Q_{i}\right)-S_{\exp }\left(Q_{i}\right)\right]^{2} / \sigma^{2}\left(Q_{i}\right),
$$

where $S_{\exp }(Q)$ is the structure factor obtained experimentally, and $S_{\mathrm{rmc}}(Q)$ is the structure factor for the model. $\sigma\left(Q_{i}\right)$ is the experimental error for the $i$-th data point, $S\left(Q_{i}\right)$, determined from counting statistics.

In this study, we started with an initial configuration of about 5000 atoms, randomly distributed in a cube of side $L \sim 4.6 \mathrm{~nm}$. Normal periodic boundary conditions were used and $L$ was chosen to be sufficiently large that there is little truncation effect in the Fourier transformation of eq. (4). The number of atoms and cube size were chosen so that the model had the experimental density. In this RMC modeling, various kinds of initial atomic configurations were used to confirm the reliability of the model structure. Moreover, the simulation was carried out by use of both neutron and X-ray diffraction data simultaneously. These procedures improve the confidence of the model structure. Accordingly, a small structural change observed in the study could be reconfirmed. The local atomic environment for the simulations was characterized by means of a Voronoi analysis. ${ }^{5)}$ The radii connecting an atom with its neighbours are bisected with planes and then the intersection of these planes forms the Voronoi polyhedron of the atom. The distribution of the Voronoi polyhedra is expressed in terms of Schläfli notation ${ }^{5)}$ whereby a polyhedron is denoted by a set of indices $n_{3}, n_{4}, n_{5}$, $n_{6}, n_{7}, n_{8}$, where $n_{i}$ is the number of faces with $i$ vertices. Note that the total coordination number of a specific atom is given by the sum of these indices, $\sum_{i} n_{i}$.

\section{Results}

Figure 1 shows the structure factors, $S(Q)$, observed by neutron and X-ray diffraction (solid lines) for $\mathrm{Ni}_{33.3} \mathrm{Zr}_{66.7}$ (a) and $\mathrm{Ni}_{25} \mathrm{Zr}_{60} \mathrm{Al}_{15}$ (b) metallic glasses. The characteristic prepeak is clearly observed at $Q \sim 17 \mathrm{~nm}^{-1}$ in $S(Q)$ s for both $\mathrm{Ni}_{33.3} \mathrm{Zr}_{66.7}$ and $\mathrm{Ni}_{25} \mathrm{Zr}_{60} \mathrm{Al}_{15}$ metallic glasses. However, it 


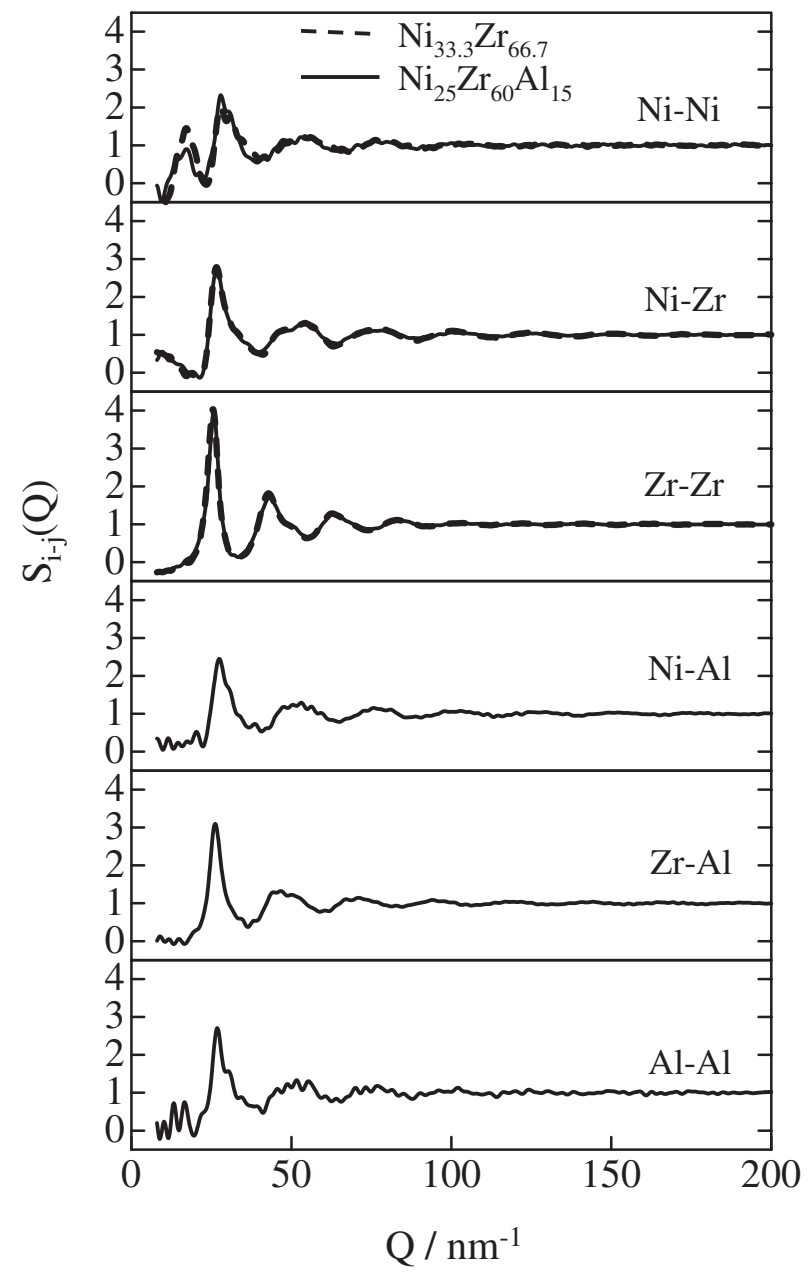

Fig. 2 Partial structure factors, $S_{i j}(Q)$, derived from the Reverse Monte Carlo (RMC) simulations for $\mathrm{Ni}_{33.3} \mathrm{Zr}_{66.7}$ (a) and $\mathrm{Ni}_{25} \mathrm{Zr}_{60} \mathrm{Al}_{15}$ (b) metallic glasses.

can be found that the intensity of the pre-peak decreased by alloying $\mathrm{Al}$ to the $\mathrm{Ni}-\mathrm{Zr}$ system and the amplitude of the oscillations above $Q \sim 60 \mathrm{~nm}^{-1}$ for the $\mathrm{Ni}-\mathrm{Zr}-\mathrm{Al}$ metallic glass became smaller than for the $\mathrm{Ni}-\mathrm{Zr}$ metallic glass. Moreover, there is no sign of a small angle scattering within the range of the experimental data $\left(Q_{\min }=5 \mathrm{~nm}^{-1}\right)$, indicating that the ternary metallic glass is homogeneous.

In order to get information of the three-dimensional atomic arrangement for these metallic glasses, RMC modeling based on the neutron and X-ray diffraction data was employed. Figure 1 also indicates the $S(Q)$ derived from the RMC models (dashed lines), and excellent agreement with the experimental $S(Q)$ observed by neutron and X-ray diffraction. The pre-peak observed at $Q \sim 17 \mathrm{~nm}^{-1}$ in the neutron $S(Q)$ for both $\mathrm{Ni}_{33.3} \mathrm{Zr}_{66.7}$ and $\mathrm{Ni}_{25} \mathrm{Zr}_{60} \mathrm{Al}_{15}$ metallic glasses was explicitly reproduced by the RMC models. Partial structure factors, $S_{i j}(Q)$, derived from the RMC model for $\mathrm{Ni}_{33.3} \mathrm{Zr}_{66.7}$ and $\mathrm{Ni}_{25} \mathrm{Zr}_{60} \mathrm{Al}_{15}$ metallic glasses are shown in Fig. 2. The pre-peak in the total $S(Q)$ for $\mathrm{Ni}_{33.3} \mathrm{Zr}_{66.7}$ and $\mathrm{Ni}_{25} \mathrm{Zr}_{60} \mathrm{Al}_{15}$ metallic glasses was found to arise from the NiNi partial structure factor, $S_{N i N i}(Q)$. But it can be seen that the intensity of the pre-peak for $\mathrm{Ni}_{25} \mathrm{Zr}_{60} \mathrm{Al}_{15}$ metallic glass becomes lower in comparison with that for $\mathrm{Ni}_{33.3} \mathrm{Zr}_{66.7}$ metallic glass due to addition of $\mathrm{Al}$.

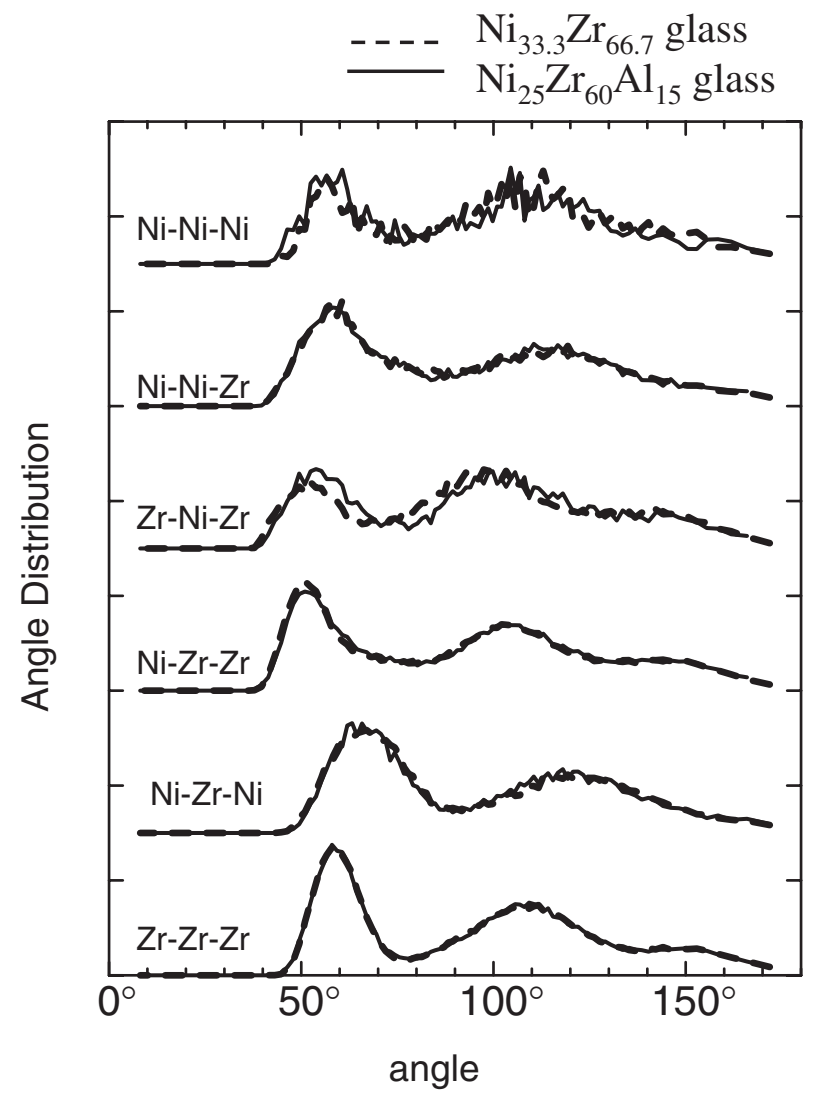

Fig. 3 Bond angle distributions for $\mathrm{Ni}_{33.3} \mathrm{Zr}_{66.7}$ (solid line) and $\mathrm{Ni}_{25^{-}}$ $\mathrm{Zr}_{60} \mathrm{Al}_{15}$ (dashed line) metallic glasses.

\section{Discussion}

When the pre-peak for $\mathrm{Ni}_{33.3} \mathrm{Zr}_{66.7}$ metallic glass is compared with that for $\mathrm{Ni}_{25} \mathrm{Zr}_{60} \mathrm{Al}_{15}$ metallic glass, we can easily recognize that the addition of $\mathrm{Al}$ to the $\mathrm{Ni}-\mathrm{Zr}$ system causes the change of the atomic configuration, definitely, as shown in Fig. 1. Moreover, partial $S_{i j}(Q)$ obtained the RMC model apparently indicates that the structural change is attributed to the Ni-Ni correlation, since there is no drastic change in the partial $S_{i j}(Q)$ s of $\mathrm{Ni}-\mathrm{Zr}$ and $\mathrm{Zr}-\mathrm{Zr}$ pair correlations as seen in Fig. 2. The result teaches us that when Al is alloyed with the $\mathrm{Ni}-\mathrm{Zr}$ system, $\mathrm{Al}$ atoms affect principally the Ni-Ni atomic arrangement. Figure 3 shows bond angle distributions for Ni-Ni-Ni, Ni-Ni-Zr, Zr-Ni-Zr, Ni-Zr-Zr, Ni$\mathrm{Zr}-\mathrm{Ni}$ and $\mathrm{Zr}-\mathrm{Zr}-\mathrm{Zr}$ derived from the RMC simulations for $\mathrm{Ni}_{33.3} \mathrm{Zr}_{66.7}$ and $\mathrm{Ni}_{25} \mathrm{Zr}_{60} \mathrm{Al}_{15}$ metallic glasses. All of the bond angle distributions show two peaks, one in the region of $50-60^{\circ}$, and the other in the region of $100-120^{\circ}$. It can be seen that the $\mathrm{Ni}-\mathrm{Ni}-\mathrm{Ni}$ and $\mathrm{Zr}-\mathrm{Ni}-\mathrm{Zr}$ bond angles changed after adding $\mathrm{Al}$ to the $\mathrm{Ni}-\mathrm{Zr}$ system. Therefore, the result also indicates that the $\mathrm{Al}$ atoms change the structure around a $\mathrm{Ni}$ atom in the $\mathrm{Ni}-\mathrm{Zr}$ glass.

Voronoi analysis applied to investigate the polyhedral environment in the RMC model for $\mathrm{Ni}_{33.3} \mathrm{Zr}_{66.7}$ and $\mathrm{Ni}_{25} \mathrm{Zr}_{60} \mathrm{Al}_{15}$ metallic glasses. Volonoi polyhedra around $\mathrm{Ni}, \mathrm{Zr}$ and $\mathrm{Al}$ atoms were analyzed independently, as shown in Fig. 4. The fractions of the polyhedra around $\mathrm{Zr}$ atoms for $\mathrm{Ni}_{33.3} \mathrm{Zr}_{66.7}$ metallic glass are quite similar to those for $\mathrm{Ni}_{25} \mathrm{Zr}_{60} \mathrm{Al}_{15}$ metallic glass as shown in Fig. 4(a). The 


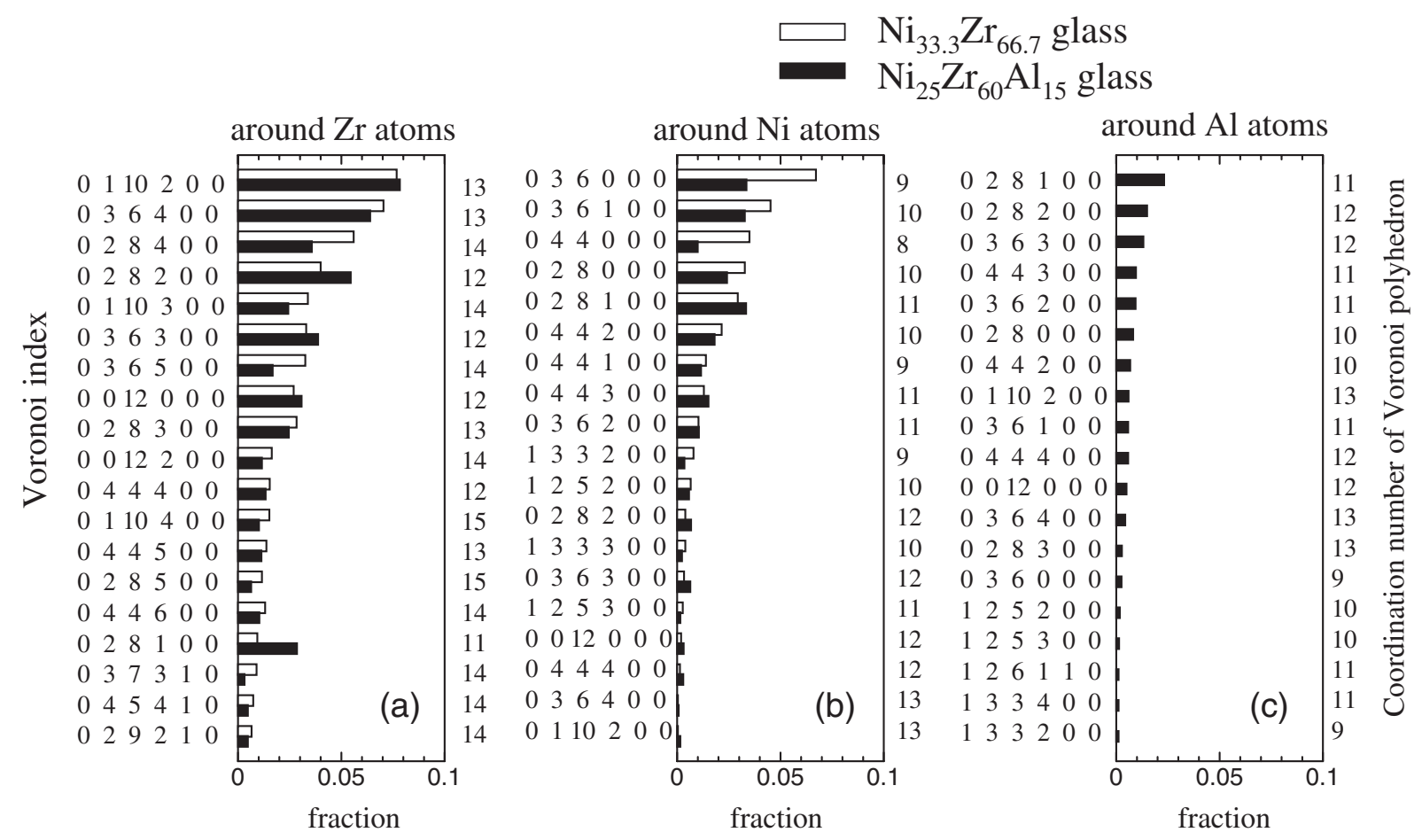

Fig. 4 Fractions of Voronoi polyhedra around $\mathrm{Zr}(\mathrm{a}), \mathrm{Ni}$ (b) and $\mathrm{Al}$ (b) atoms for $\mathrm{Ni}_{33.3} \mathrm{Zr}_{66.7}$ and $\mathrm{Ni}_{25} \mathrm{Zr}_{60} \mathrm{Al}_{15}$ metallic glasses.

polyhedra around $\mathrm{Zr}$ atoms predominantly have total coordination numbers in the range of 12-14 atoms, typical of icosahedron-like geometry. The fractions of the polyhedra around $\mathrm{Zr}$ atoms are quite similar with each other for $\mathrm{Ni}_{33.3} \mathrm{Zr}_{66.7}$ and $\mathrm{Ni}_{25} \mathrm{Zr}_{60} \mathrm{Al}_{15}$ metallic glasses. The same result has been reported in the previous paper, ${ }^{6}$ ) which was discussed the structure of $\mathrm{Ni}_{33.3} \mathrm{Zr}_{66.7}$ and $\mathrm{Cu}_{33.3} \mathrm{Zr}_{66.7}$ metallic glasses. Therefore, we can easily recognize that the fundamental structure is constructed by the packing of $\mathrm{Zr}$ atoms with icosahedron-like environment for both $\mathrm{Ni}_{33.3}$ $\mathrm{Zr}_{66.7}$ and $\mathrm{Ni}_{25} \mathrm{Zr}_{60} \mathrm{Al}_{15}$ metallic glasses. These polyhedra have various kinds of pentagonal symmetry planes, the fivefold symmetry of which is recognized to be important for stabilizing the glassy state. Thus far, the structural study has also suggested the existence of the icosahedral atomic configuration from the coordination number of 12.5 atoms around $\mathrm{Zr}$ in $\mathrm{Ni}_{25} \mathrm{Zr}_{60} \mathrm{Al}_{15}$ metallic glass. ${ }^{2)}$

The Voronoi polyhedra around $\mathrm{Ni}$ atoms differ evidently between $\mathrm{Ni}_{33.3} \mathrm{Zr}_{66.7}$ and $\mathrm{Ni}_{25} \mathrm{Zr}_{60} \mathrm{Al}_{15}$ metallic glasses as shown in Fig. 4(b). For $\mathrm{Ni}_{33.3} \mathrm{Zr}_{66.7}$ metallic glass the Voronoi polyhedra around $\mathrm{Ni}$ atoms are dominated by the

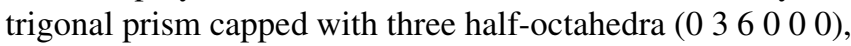
the Archimedian antiprism capped with two half-octahedra $(0$

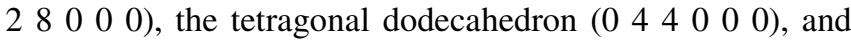
analogous polyhedra. The coordination numbers for these dominant Voronoi polyhedra are respectively 9 atoms for (0 3 $6000)$ polyhedron, 8 atoms for $(044000)$ polyhedron and 10 atoms for $\left(\begin{array}{l}0 \\ 2\end{array} 80000\right)$ polyhedron, with an average of less than 10 atoms. These polyhedra correspond well with the structure of crystalline $\mathrm{NiZr}_{2}{ }^{7)}$ Moreover, this figure clearly indicates that after adding $\mathrm{Al}$ to $\mathrm{Ni}-\mathrm{Zr}$ system the polyhedra characterized by the trigonal prism drastically decrease in the $\mathrm{Ni}_{25} \mathrm{Zr}_{60} \mathrm{Al}_{15}$ metallic glass. It is worth noting that the fractions of the polyhedra with the coordination number more

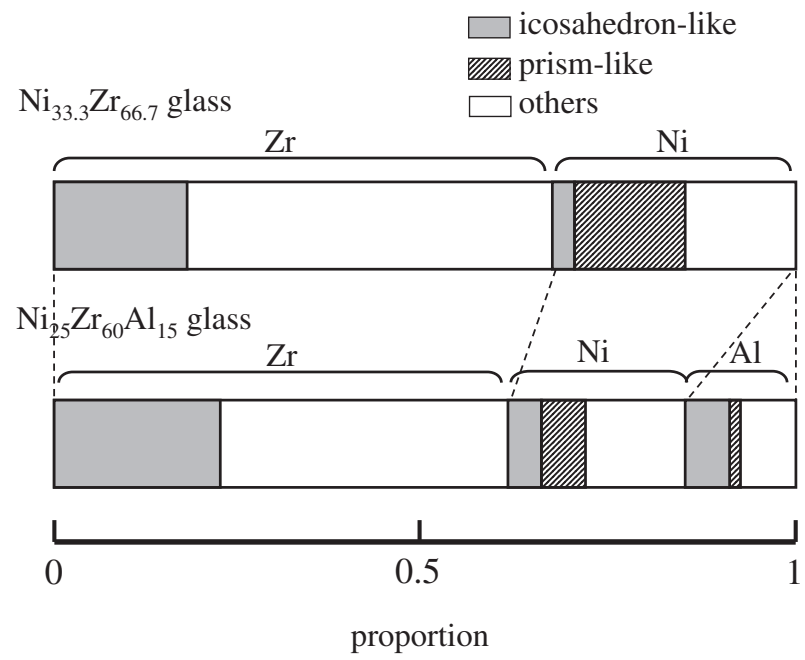

Fig. 5 The proportion of icosahedron-like, prism-like polyhedra and the others around $\mathrm{Zr}$, $\mathrm{Ni}$ and $\mathrm{Al}$ atoms for $\mathrm{Ni}_{33.3} \mathrm{Zr}_{66.7}$ and $\mathrm{Ni}_{25} \mathrm{Zr}_{60} \mathrm{Al}_{15}$ metallic glasses.

than 11 increase due to the addition of Al. Figure 4(c) shows the polyhedra around $\mathrm{Al}$ atoms for $\mathrm{Ni}_{25} \mathrm{Zr}_{60} \mathrm{Al}_{15}$ metallic glass. It can be recognized that the polyhedra of icosahedronlike geometry with more than 11 atoms is dominant in the structure around $\mathrm{Al}$ atoms. The Volonoi analysis of the atomic arrangement of the RMC model for $\mathrm{Ni}_{25} \mathrm{Zr}_{60} \mathrm{Al}_{15}$ metallic glass definitely demonstrates an increase of the icosahedron-like polyhedra which have higher coordination number greater than 11 atoms.

Figure 5 shows the proportion of the icosahedron-like

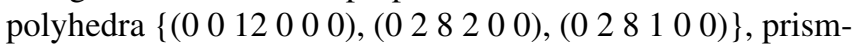

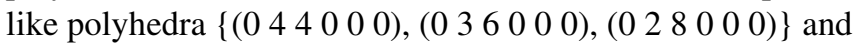


the others in the RMC model for $\mathrm{Ni}_{33.3} \mathrm{Zr}_{66.7}$ and $\mathrm{Ni}_{25} \mathrm{Zr}_{60^{-}}$ $\mathrm{Al}_{15}$ metallic glasses. The result allows us to clearly understand the increase of the icosahedron-like and the drastic decrease of the prism-like polyhedra after alloying $\mathrm{Al}$ with the $\mathrm{Ni}-\mathrm{Zr}$ system. Especially, since the decrease of the

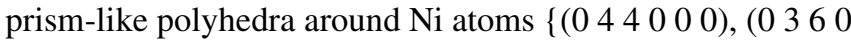

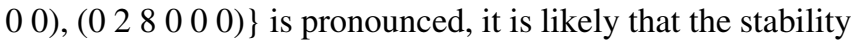
of the Ni-Zr-Al metallic glasses is strongly affected by decreasing the polyhedra correspond well with the structure of crystalline $\mathrm{NiZr}_{2}$ as well as by increasing the icosahedronlike polyhedra. The result is fairly supported by our previous result that icosahedron-like polyhedra dominate for the environment around $\mathrm{Cu}$ atoms for $\mathrm{Cu}_{33.3} \mathrm{Zr}_{66.7}$ metallic glass in comparison with for that around $\mathrm{Ni}$ atoms for $\mathrm{Ni}_{33.3} \mathrm{Zr}_{66.7}$ metallic glass. ${ }^{6)}$

\section{Conclusions}

The Voronoi analysis of the model structure obtained by RMC modeling based on the neutron and X-ray diffraction data for $\mathrm{Ni}_{33.3} \mathrm{Zr}_{66.7}$ and $\mathrm{Ni}_{25} \mathrm{Zr}_{60} \mathrm{Al}_{15}$ metallic glasses was investigated from the viewpoint of the stability of the glassy state. It informed us that the $\mathrm{Zr}$ atoms form a very similar fundamental structure with icosahedron-like geometry in both systems and such polyhedra with a total coordination number in excess of 12 play a role to form the glassy configuration. The polyhedra around $\mathrm{Ni}$ atoms are dominated by trigonal prism-like, Archimedian antiprism-like, and similar polyhedra, which correspond with the structure of the crystalline $\mathrm{NiZr}_{2}$, with total coordination numbers less than 10 for $\mathrm{Ni}_{33.33} \mathrm{Zr}_{66.7}$ metallic glass. However, after alloying $\mathrm{Al}$ with the $\mathrm{Ni}-\mathrm{Zr}$ system, the drastic decrease of the prism-like polyhedra around $\mathrm{Ni}$ atoms and the domination of the icosahedron-like polyhedra around $\mathrm{Zr}$ and $\mathrm{Al}$ atoms were observed. Therefore, these results indicate that icosahedronlike polyhedra play an important role for stabilizing the glass configuration.

\section{Acknowledgments}

This work was supported by a Grant-in-Aid for Scientific Research in Priority Area and Creative Scientific Research from the Ministry of Education, Science, Sports and Culture.

\section{REFERENCES}

1) J. Saida, M. Kasai, E. Matsubara and A. Inoue: Ann. Chim. Sci. Mat. 27 (2002) 77-89.

2) E. Matsubara, T. Tamura, Y. Waseda, A. Inoue, T. Zhang and T. Masumoto: Mater. Trans., JIM 33 (1992) 873-878.

3) R. L. McGreevy and L. Pusztai: Mol. Simulation 1 (1988) 359-367.

4) T. E. Faber and J. M. Ziman: Phil. Mag. 11 (1965) 153-173.

5) V. S. Stepanyuk, A. Szasz, A. A. Katsnelson, O. S. Trushin, H. Müller and H. Kirchmayr: J. Non-Cryst. Solids 159 (1993) 80-87.

6) T. Fukunaga, K. Itoh, T. Otomo, K. Mori, M. Sugiyama, H. Kato, M. Hasegawa, A. Hirata, Y. Hirotsu and A. C. Hannon: Intermetallics 14 (2006) 893-897.

7) P. Villars and L. D. Calvert: Pearson's Handbook of Crystallographic Data for Intermetallic phases (American Society for Metals, 1985). 